\title{
UPGRADING OF A NIGERIAN IXIOLITE ORE TO COLUMBITE BY SULPHURIC ACID TREATMENT
}

\author{
Alafara A. Baba ${ }^{1 *}$, Oluwaseun Ajibola ${ }^{1}$, Abdullah S. Ibrahim², \\ Folahan A. Adekola ${ }^{1}$, Ruth O. Sanni ${ }^{1}$ and Yunusa Abdulganiyu ${ }^{3}$ \\ ${ }^{1}$ Department of Industrial Chemistry, University of Ilorin, P.M.B. 1515, \\ Ilorin-240003, Nigeria. \\ 2. Department of Chemistry, University of Ilorin, P.M.B. 1515, \\ Ilorin-240003, Nigeria. \\ ${ }^{3 .}$ Department of Geology, Federal University, Birnin-Kebbi, P.M.B. 1157, \\ Birnin-Kebbi, Kebbi State, Nigeria.
}

Received 22.07.2016

Accepted 25.08.2016

\begin{abstract}
Leaching of a Nigerian Ixiolite ore by sulphuric acid solution was carried out and the effect of some parameters such as acid concentration, temperature and particle size was evaluated as a function of time. The experimental results showed that the Ixiolite dissolution increases with increasing acid concentration, temperature, leaching time and, decreases with particle size. With $3 \mathrm{~mol} / \mathrm{L} \mathrm{H}_{2} \mathrm{SO}_{4}$ solution, $71.14 \%$ of the ore reacted within 120 minutes at $80^{\circ} \mathrm{C}$.The kinetics of dissolution of the mineral was also examined and the observed effects of the operating variables on the leaching rate were consistent with the diffusion controlled kinetic model. The calculated activation energy for the leaching process was $24.40 \mathrm{~kJ} / \mathrm{mol}$ with the reaction order of 0.5 , supporting the proposed model. Detailed characterization of the ore before and after leaching were carried out. At optimal leaching conditions, thermodynamic feasibility of the conversion of raw Ixiolite to Columbite of industrial value as confirmed by X-ray diffraction (XRD) analysis is possible.

Keywords: Ixiolite, Columbite, Nigeria, Leaching, Sulphuric acid.
\end{abstract}

* Correspondence authors: A. A. Baba, alafara@unilorin.edu.ng 


\section{Introduction}

Ixiolite ( $\mathrm{Ta}, \mathrm{Nb}, \mathrm{Sn}, \mathrm{Mn}, \mathrm{Fe})_{4} \mathrm{O}_{8}$ is an important ore of niobium-tantalum containing mineral (coltan), commonly associated with igneous rocks including granites, pegmatites, syenites and carbonatites [1]. Over the last 20 years, Ixiolite has been of interest to the modern scientists due to its prominence in the production of modern industrial materials and "high-tech" end user products. These ranges from super alloys in the production of jet engines, nuclear reactors and space vehicle frames to hearing aids, laptop computers, mobile phones, video consoles, GPS and digital cameras, among others [2]. However, high percentage of $\mathrm{Ta}_{2} \mathrm{O}_{5}$ in Ixiolite has appreciably increased its market value than other coltans such as euxenite (Y,Ca,Ce,U,Th) $(\mathrm{Nb}, \mathrm{Ti}, \mathrm{Ta})_{2} \mathrm{O}_{6}$, pyrochlore $(\mathrm{Na}, \mathrm{Ca})_{2} \mathrm{Nb}_{2} \mathrm{O}_{6}(\mathrm{O}, \mathrm{OH}, \mathrm{F})$, stuverite $(\mathrm{Ti}, \mathrm{Ta}, \mathrm{Fe}) \mathrm{O}_{2}$, lueshite $\left(\mathrm{NaNbO}_{3}\right)$ and columbite $\left.(\mathrm{Fe}, \mathrm{Mn})(\mathrm{Nb}, \mathrm{Ta})_{2}\right)_{6}[3,4]$. For example, the market potential for pure tantalum metal has been steadily growing with increasing application in the electrical and electronic fields and in materials for the chemical industry. Tantalum in sheet and tube form is used for lining chemical reaction vessels and in condensers and heat exchangers. The high reliability, excellent rectification properties, high capacitance and the wide temperature range of application of tantalum capacitors are contributing to a phenomenal growth in demand for them all over the world [5].

Apart from Australia known to have the largest coltan ore deposits, other countries with large reserves are Brazil, Canada, Mozambique, Portugal, Thailand, Zaire and Nigeria [6]. In Nigeria, large deposits of coltan have been reported in Nasarawa, Osun, Ekiti, Oyo, Cross-river and Federal Capital Territory, Abuja. The deposits in each of these locations are both alluvial and primary in numerous pegmatite bodies. Until recently, coltan were also discovered from a broad 400km long North east - Southwest trending belt stretching from the Wamba - Keffi - Nasarawa area (near the Jos Plateau) through Isanlu - Egbe in Central Nigeria to the Ijero - Aramoko - Ilesha areas of Southwest Nigeria and a few occurrences in the Obudu and Oban massifs of Southeast Nigeria [7-8].

Due to increasing demands of pure coltan products to meeting various diverse industrial needs, efforts of researchers has been geared towards achieving the objectives of the availability of pure coltan products. Within the last decade, ore processors have made considerable progress in the processing of coltan minerals using different methods such as pyrometallurgy, chlorination or hydrometallurgy. It has been observed that during chlorination of Low Grade Concentrate (LGC) and High Grade Concentrate (HGC), coltan products from Low Grade Concentrates are often found contaminated with chloride compounds of manganese and iron, while pure coltan compounds can be obtained from High Grade Concentrate [9]. However, hydrometallurgy method which involves the selective leaching using acids such as hydrochloric and nitric acid has been the most economically viable route for the processing of coltan ores $[10,11]$. The appropriate pregnant solution containing the desired metal of interest emanating from the leaching process can further be purified using selective extractants by solvent extraction process [12]. 
In this work, enrichment of a Nigerian Ixiolite ore for possible conversion to high grade columbite of industrial value by leaching with sulphuric acid solution was examined. The effects of acid concentration, reaction temperature and particle size on the extent of the ore dissolution were examined.

\section{Materials and Method}

The Ixiolite ore used for this investigation was sourced from Aba-Paanu, Oluyole Local Government Area of Oyo State, Nigeria. The sample was crushed, grinded and pulverized using ASTM standard species into particle sizes: $<0.09 \mathrm{~mm}, 0.25 \mathrm{~mm}$ and $0.30 \mathrm{~mm}$. The $<0.09 \mathrm{~mm}$ fraction was used in performing all experiments due to its high surface area, unless otherwise stated.

Leaching experiments were conducted in a well-sealed, acid-resistant borosilicate $250 \mathrm{ml}$ glass reactor equipped with a mechanical stirrer for stirring, a thermometer for temperature control and a condenser to prevent heat loss by evaporation. The required temperature of the reactor contents within $\pm 0.5{ }^{\circ} \mathrm{C}$ was adjusted by a thermostatically controlled electric heating mantle. For each experiment, the reactor was filled with 100 $\mathrm{ml}$ sulphuric acid with pre-determined concentrations ( $0.1-4.0 \mathrm{~mol} / \mathrm{L})$. In each run, 10 $\mathrm{g} / \mathrm{L}$ of the ore was charged into the reactor and heated to the desired temperature $(55$ ${ }^{\circ} \mathrm{C}$ ) using $\mathrm{H}_{2} \mathrm{SO}_{4}$ solution, at various reaction times up to 120 minutes. Preliminary experiments were carried out to determine the optimal leaching conditions. The concentration that gives the maximum dissolution was used for the optimization of other leaching parameters including temperature and particle size. At the completion of the leaching tests, the leached product was filtered, water-washed, and oven-dried to constant weight before being analyzed.

The fraction of the Ixiolite reacted was calculated from the loss in weight of the initial amount of sample dissolved or undissolved during leaching. [10,13]. The raw Ixiolite ore and some selected leached products were analyzed using XRF (MINIPAL 4) and XRD (EMPYREAN Diffractometer) and SEM (FEI NOVA NANOSEM 230) with a field emission gun coupled by an EDS detector for preparation of SEM images and analysis.

\section{Results and discussion}

\section{Characterization investigation}

The elemental composition of the Ixiolite ore is: $\mathrm{Ta}_{2} \mathrm{O}_{5}(22.40 \%), \mathrm{Nb}_{2} \mathrm{O}_{5}$ (41.40\%), $\mathrm{Al}_{2} \mathrm{O}_{3}(2.10 \%), \mathrm{SiO}_{2}(12.00 \%), \mathrm{Rb}_{2} \mathrm{O}$ (4.90\%), $\mathrm{MnO}(6.20 \%)$, and $\mathrm{Fe}_{2} \mathrm{O}_{3}$ $(8.70 \%)$ as major constituents. Other compounds detected occurring from low to trace level includes $\mathrm{K}_{2} \mathrm{O}(0.28 \%), \mathrm{CaO}(0.44 \%), \mathrm{TiO}_{2}(0.79 \%), \mathrm{V}_{2} \mathrm{O}_{5}(0.05 \%), \mathrm{Cr}_{2} \mathrm{O}_{3}(0.03 \%)$ $\mathrm{ZnO}(0.07), \mathrm{In}_{2} \mathrm{O}_{3}(0.10)$ and $\mathrm{BaO}(0.15 \%)$.

The X-ray diffraction analysis indicated that the mineralogical constituent is made up of Ixiolite $\left(\mathrm{Ta}_{1.76} \mathrm{Fe}_{0.72} \mathrm{Sn}_{0.52} \mathrm{Mn}_{0.48} \mathrm{O}_{8}\right)$ with considerable amount of Quartz $\left(\mathrm{SiO}_{2}\right)$ as shown in Figure 1. The EDX analysis of the ore corroborates the result of the EDXRF to give Ta (19.96\%), Nb (28.9\%), Fe (6.34\%), Mn (10.16\%), and O (34.64\%). 


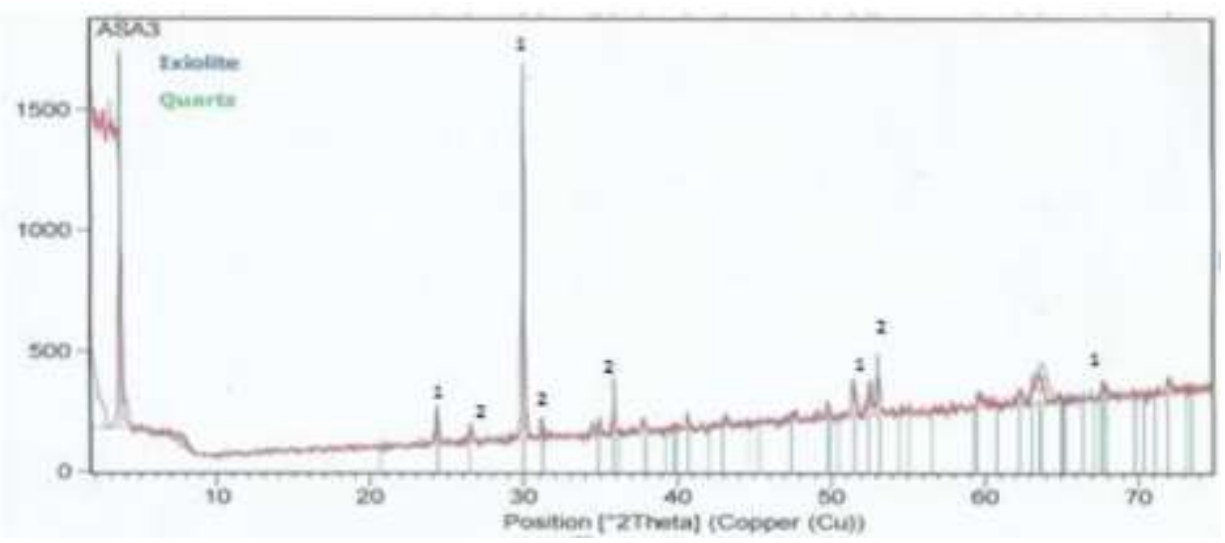

Fig. 1. The XRD spectral of Ixiolite ore with important compound detected before leaching. The Joint Committee on Powder Diffraction Standard, JCDPS, File numbers are in curl brackets: Ixiolite [1] \{073-6628\}, Quartz [2] \{074-1811\}.

The Joint Committee on Powder Diffraction Standard. JCDPS File numbers are in curl brackets. Ixiolite [1] \{073-6628\}, Quartz [2] \{074-1811\}.

The Scanning electron microscopy studies revealed a dominantly flakes of Ixiolite and quartz with dominantly porous ridged surface (A), (B): agglomeration of irregular-like crystals showing high product crystallinity.

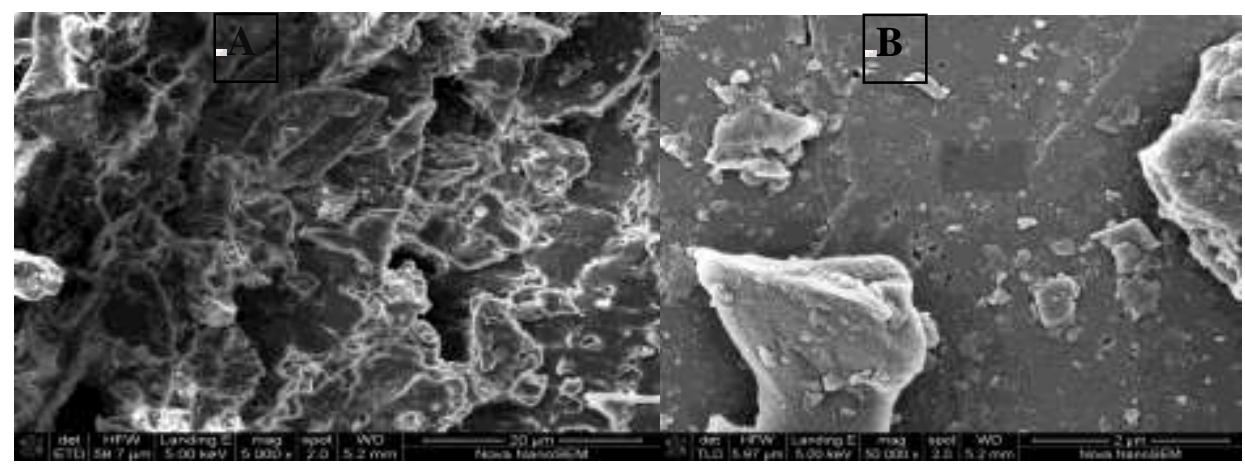

Fig. 2. SEM image of Ixiolite ore before leaching (A), and after optimal leaching (B).

Also, at optimal leaching conditions $\left(3 \mathrm{~mol} / \mathrm{L} \mathrm{H}_{2} \mathrm{SO}_{4}, 80^{\circ} \mathrm{C}, \leq 0.09 \mathrm{~mm} 120\right.$ minutes), the XRD and EDS spectra shows predominantly Columbite peaks as shown in Figure 3. 

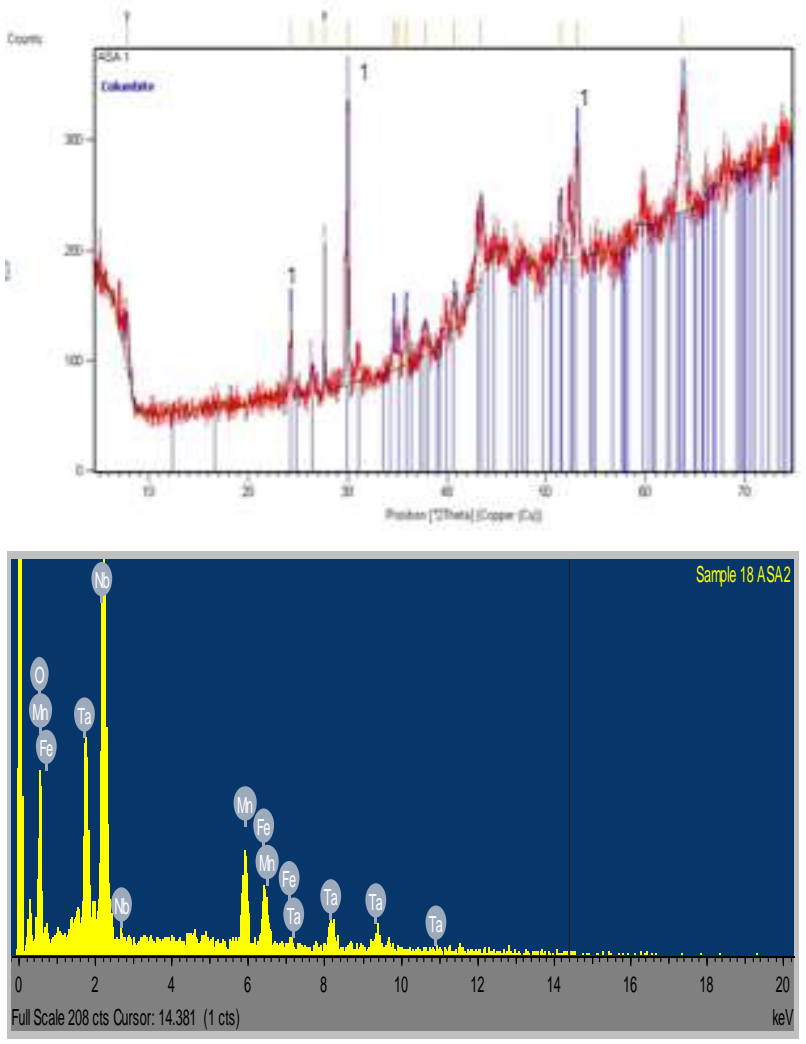

Fig. 3. XRD and EDS spectra of Ixiolite ore at optimum leaching conditions.

\section{Leaching studies}

\section{Effect of sulphuric acid concentration}

The effect of sulphuric acid solution $(0.1-4 \mathrm{~mol} / \mathrm{L})$ on the Ixiolite dissolution was studied using a moderate stirring speed and $<0.09 \mathrm{~mm}$ particle size at a temperature of $55^{\circ} \mathrm{C}$. The result obtained is plotted in Figure 5. The result shows that the rate of dissolution increases with time. The rate of dissolution reaches about $50.2 \%$ and $51.3 \%$ at $3 \mathrm{~mol} / \mathrm{L}$ and $4 \mathrm{~mol} / \mathrm{L} \mathrm{H}_{2} \mathrm{SO}_{4}$ solution, respectively. However, since the extent of the ore reacted at the above concentrations are almost equal and for economic considerations, $3 \mathrm{~mol} / \mathrm{L} \mathrm{H}_{2} \mathrm{SO}_{4}$ solution was considered as optimum acid concentration and was used for further leaching investigations [14]. 


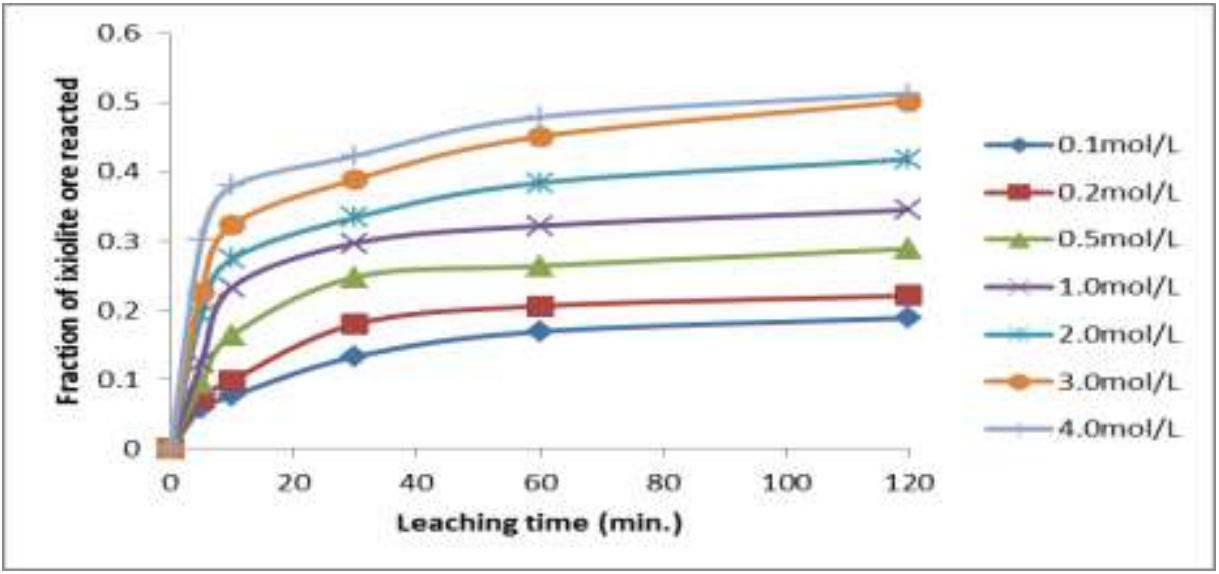

Fig. 4. Effect of $\mathrm{H}_{2} \mathrm{SO}_{4}$ concentration on Ixiolite dissolution at various leaching time

Experimental conditions: Temperature $=55^{\circ} \mathrm{C}$, particle size $=<0.09 \mathrm{~mm}$, solidliquid ratio $=10 \mathrm{~g} / \mathrm{L}$.

\section{Effect of leaching temperature}

The effect of temperature on the rate of Ixiolite dissolution was studied over the temperature range of $25{ }^{\circ} \mathrm{C}-80{ }^{\circ} \mathrm{C}$, using moderate stirring speed (Figure 5). The experimental result obtained showed that the fraction of ore dissolved increases with increasing temperature. It was observed that dissolution rate is sensitive to reaction temperature change. Thus, rate of dissolution increases as a function of temperature, and the dissolution reached $71.4 \%$ within 120 minutes at $80^{\circ} \mathrm{C}$. The residual product was analyzed and found to contain silica ( $\left(\mathrm{a}-\mathrm{SiO}_{2}: 41-1043\right)$. However, temperature above 80 ${ }^{\circ} \mathrm{C}$ was not considered in this study, as loss of acid through evaporation was envisaged.

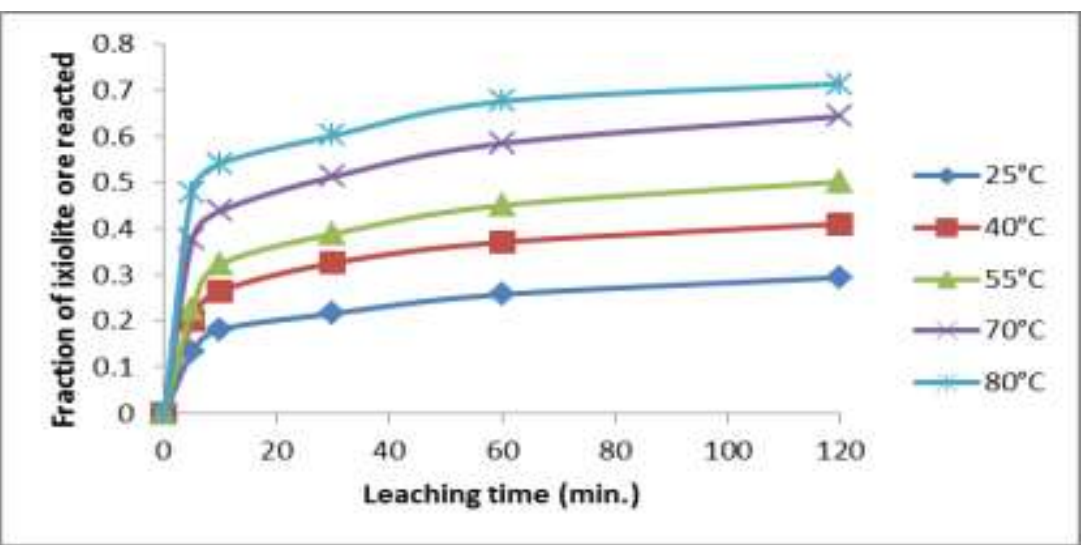

Fig. 5. Fraction of Ixiolite dissolved versus leaching time at different temperatures

Experimental conditions: $\left[\mathrm{H}_{2} \mathrm{SO}_{4}\right]=3 \mathrm{~mol} / \mathrm{L}$, particle size $=<0.09 \mathrm{~mm}$, solid/liquid ratio $=10 \mathrm{~g} / \mathrm{L}$ 


\section{Effect of particle size}

The effect of particle size on the rate of Ixiolite ore dissolution was examined by $3 \mathrm{~mol} / \mathrm{L}$ sulphuric acid at $80^{\circ} \mathrm{C}$ using $<0.09 \mathrm{~mm}, 0.112 \mathrm{~mm}, 0.25 \mathrm{~mm}$ and $0.30 \mathrm{~mm}$. The experimental result obtained is shown in Figure 6. It is evident from the result that the rate of Ixiolite dissolution decreases with increase in particle size. This affirms that the rate of Ixiolite ore dissolution is inversely related to the initial particle size of the ore [15].

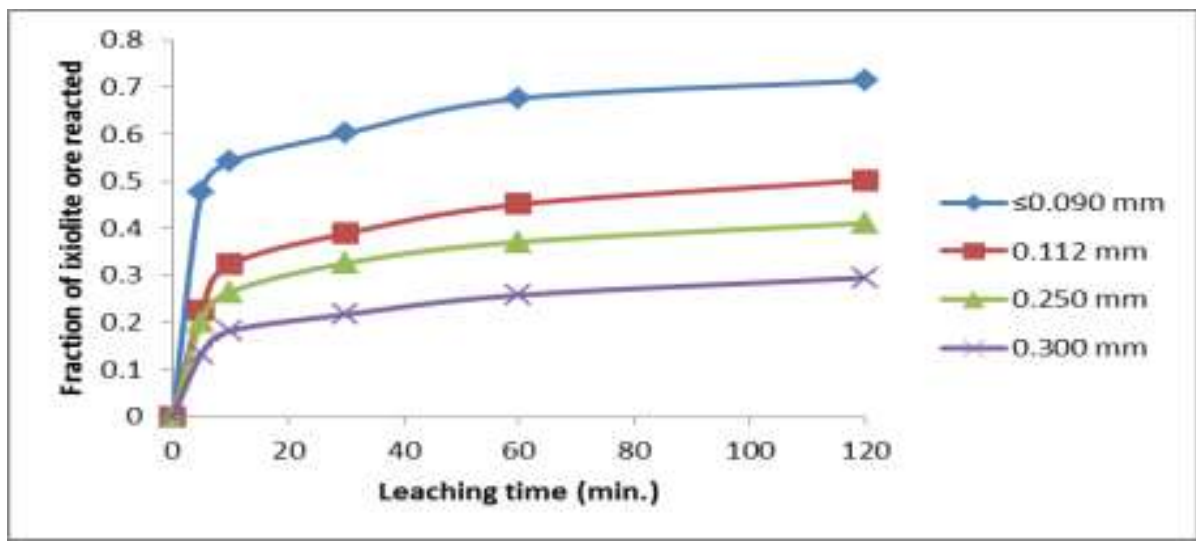

Fig. 6. Fraction of Ixiolite dissolved versus leaching time at different particle size

Experimental conditions: $\left[\mathrm{H}_{2} \mathrm{SO}_{4}\right]=3 \mathrm{~mol} / \mathrm{L}$, particle size $=(<0.09 \mathrm{~mm}, 0.25 \mathrm{~mm}$, $0.30 \mathrm{~mm}$ ), temperature $=80^{\circ} \mathrm{C}$, solid $/$ liquid ratio $=10 \mathrm{~g} / \mathrm{L}$.

\section{Kinetic model Analysis}

The dissolution rates for the Ixiolite ore treatment in sulphuric acid solution were subjected to the shrinking core model as previously reported in the literature [15-19]. The simplified equations of shrinking core model when either diffusion or the surface chemical reactions are shown in equations (1) and (2) respectively:

$$
-2 / 3 \alpha-(1-\alpha)^{2 / 3}=k_{d} t
$$

$$
1-(1-\alpha)^{1 / 3}=k_{r} t
$$

Where $\alpha=$ fraction of Ixiolite ore dissolved, $\mathrm{t}=$ reaction time, $\mathrm{k}_{\mathrm{d}}=$ rate constant for the diffusion controlled process, $\mathrm{k}_{\mathrm{r}}=$ rate constant for the surface chemical reaction process. The dissolution data was analyzed with the aforementioned models. Of the two tested models, the dissolution data in this study fitted perfectly the shrinking core model expressed by equation (1) with an average correlation of 0.9933 , greater than that of equation (2) with average correlation of about 0.5641 . Hence, the kinetic model expressed by equation (1) was used in the treatment of the dissolution data obtained in this study. 
From Arrhenius equation, the rate constant, $\mathrm{k}_{\mathrm{d}}$ term is determined from the following stochiometry:

$$
k_{d}=A e^{-E a / R T}
$$

Where $\mathrm{A}=$ frequent factor, $\mathrm{R}=$ gas constant, $\mathrm{Ea}=$ activation energy. Consequently, a plot of $\ln \mathrm{K}_{\mathrm{d}}$ versus $1 / \mathrm{T}$ gives a straight line with a slope of -Ea/RT, and intercept $\ln \mathrm{A}$ as shown in Figure 8.

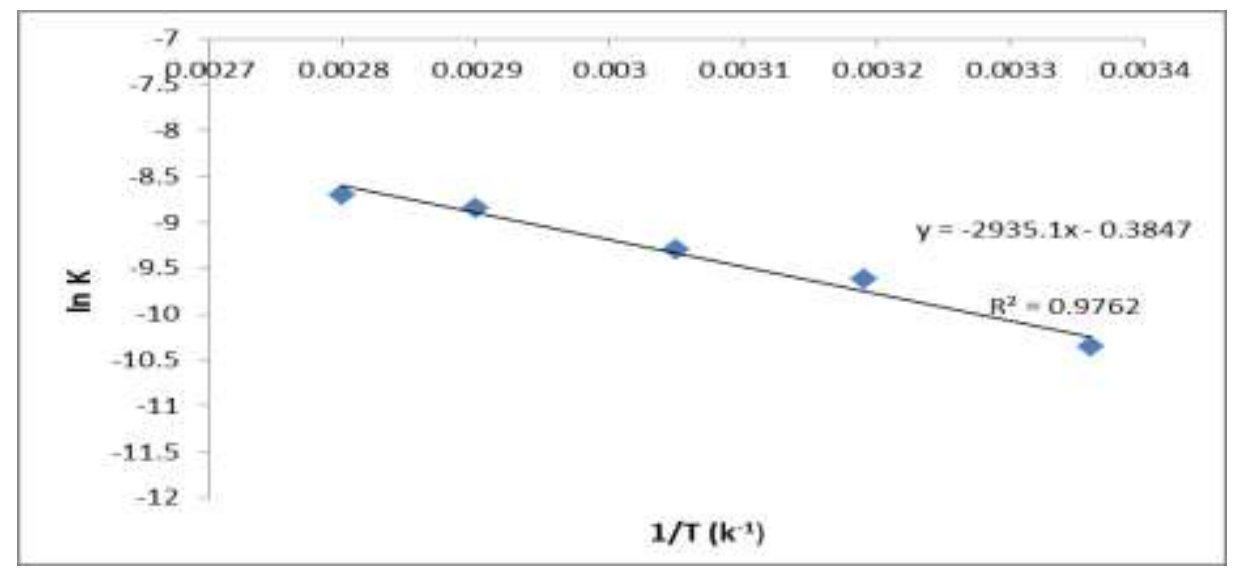

Fig. 7. Plot of In $K$ versus $1 / T\left(k^{-1}\right)$

From the Arrhenius relation shown in Figure 7, the following values were also calculated:

$$
E_{a}=24.40 \mathrm{kJmol}^{-1} \text { and } A=1.47 \mathrm{~s}^{-1}
$$

Substitution of the values of the evaluated activation energy and pre exponential factor obtained, the kinetic model for the leaching process (equation 2), supporting the diffusion controlled reaction $[17,18]$ is consistent with the following stoichiometry:

$$
1-2 / 3 \alpha-(1-\alpha)^{2 / 3}=1.47 e^{-24.40 / R T} t
$$

To determine the reaction order with respect to $\left[\mathrm{H}^{+}\right]$ion concentration, the shrinking core model $1-2 / 3 \alpha-(1-\alpha)^{2 / 3}$ versus leaching time at different concentrations was linearized (Figure 8). 


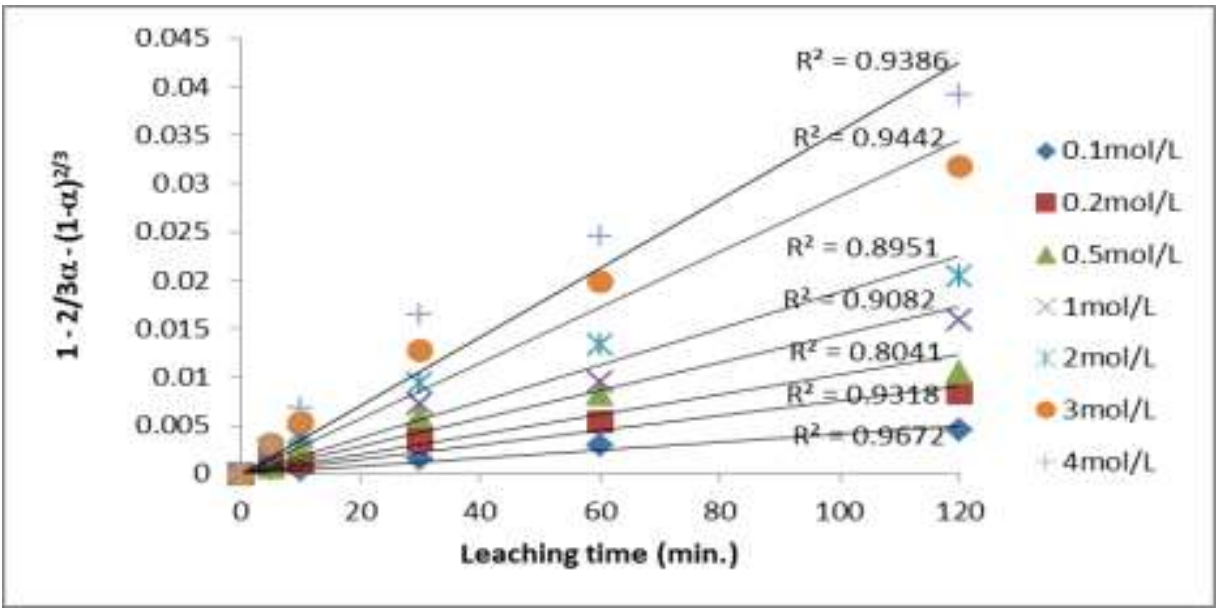

Fig. 8. Plot of $1-2 / 3 \alpha-(1-\alpha)^{2 / 3}$ versus leaching time(min) at different $\mathrm{H}_{2} \mathrm{SO}_{4}$ concentrations

From figure 8 , the slope of each of the lines were calculated and recorded as apparent rate constants $k_{d}$ from which a plot of $\ln \mathrm{K}$ versus $\ln \left[\mathrm{H}_{2} \mathrm{SO}_{4}\right]$ was obtained (Figure 9).

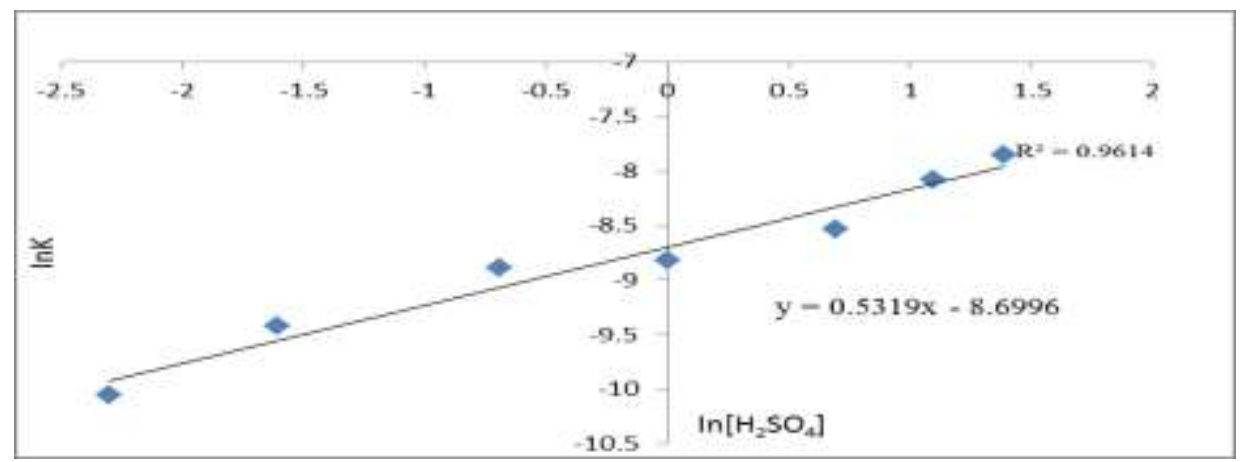

Fig. 9. Plot of $\ln \mathrm{K}$ versus $\ln \left[\mathrm{H}_{2} \mathrm{SO}_{4}\right]$

From figure 9 , the order of the reaction with respect to $\left[\mathrm{H}^{+}\right]$ion concentration from $0.1-3.0 \mathrm{~mol} / \mathrm{L} \mathrm{H}_{2} \mathrm{SO}_{4}$ was estimated to be 0.5 .

\section{Conclusion}

In this study, the leaching of an Aba-Paanu (Nigeria) Ixiolite ore was carried out in suphuric acid medium. The results obtained were exemplified and tested with appropriate models. These results have revealed that the rate of Ixiolite dissolution increases with hydrogen ion $\left[\mathrm{H}^{+}\right]$concentration, reaction temperature, leaching time and decreases with particle size. With $3 \mathrm{~mol} / \mathrm{L} \mathrm{H}_{2} \mathrm{SO}_{4}$ solution, $71.4 \%$ of the Ixiolite ore was reacted within 120 minutes at optimal leaching conditions. The unreacted component $(\sim 29 \%)$ was analyzed and found to contain silica. The dissolution kinetics was also analyzed and found to be governed by the shrinking core model for the diffusion 
controlled process. The reaction order with respect to $\left[\mathrm{H}^{+}\right]$ion and the activation energy for the dissolution process was found to be 0.5 and $24.40 \mathrm{~kJ} / \mathrm{mol}$, respectively. Based on the aforementioned data, the results of the sulphuric acid leaching obtained in the study affirmed the possibility of Ixiolite conversion to Columbite at defined optimal conditions.

\section{References}

[1] Richard Shaw, Kathryn Goodenough, Gus Gunn, Teresa Brown, and Debbie Rayner, Niobium-tantalum: Definition, mineralogy and deposits. British Geological Survey, (2011). www.mineralsuk.com

[2] M. Nete, W. Purcell, E. Snyders, J. T. Nel, G. B. Beukes, Journal of South Africa Institute of Mining Metal, Johannesburg, 112(12) (2012) 23-30.

[3] E. H. Nickel, J. F. Rowland, R. C. McAdam, Journal of the Mineralogical Society of America. 48(9-10), (1963) 961.

[4] TLC. Tantalum-Raw material and processing. http://www.tanb.org. Chaussee de Louvain 490, 1380 Lasne, Belgium. Retrieved on 21/05/2014.

[5] A. D. Damodaran, S. C. Deshpande, A.A. Majmudar, M.S. Sastri, P.K. Jera, P. Chandra, B. S. Gupta, C. K, and Taneja, A. K., Bulletin of Chemistry and Metallurgy, India, 36A (5) (1969), 306-318.

[6] A. R. Adetunji, W. O. Sinyabola, I. I. Funtua, S. O. O. Olusunle, A. A. Afonja, O. O. Adewoye, Journal of Minerals \& Materials Characterization and Engineering, $4(2)(2005)$ 85-92.

[7] Foraminifera, (2012). Coltan mining in Nigeria: the opportunities. http://foramfera.com/index.php/investment-oppurtunities-in-nigeria-theopportunities Retrieved on 05/07/2014.

[8] O. S. Ayanda, F. A. Adekola, International Journal of Metallurgical Engineering,1(3), (2012) 35-39.

[9] J. Ige, M. S. Akanni, M. K. Morakinyo, O. Owoyomi, Journal of Applied Sciences, 5(3) (2005) 496-502.

[10] A. A. Baba, F. A. Adekola, M. Faseki, Ife Journal of Science, 7(2) (2005) 221-227.

[11] N. S. Maina, (2014) Separation of Tantalum and Niobium from Nigerian Tantalite using aqueous biphase system. Ph.D Dissertation - Ahmadu Bello University, Zaria, Nigeria.

[12] M. Nete, W. Purcell, J.T. Nel, Hydrometallurgy, 149 (2014) 31-40.

[13] A. A. Baba, M. A. Mosobolaje, A. S. Ibrahim, S. Girigisu, O.A.A. Eletta, F. I. Aluko, F. A. Adekola, J. Chem. Tech. \& Metall., 50(5) (2015) 623-630.

[14] S. Aydogan, A. Aras, M. Cambazoglu, Chemical Engineering Journal, 114, (2005) 67-72

[15] A. A Baba, F. A. Adekola, Hydrometallurgy, 101 (2010) 69-75.

[16] O. Levenspiel, Chemical Reaction Engineering. $2^{\text {nd }}$ ed., Willey, New York, NY, (1972).

[17] G. Ucar, Hydrometallurgy, 95 (2009) 39-43.

[18] E. O. Olaonipekun. Bulletin of Chemical Society, Ethiopia, 14(1) (2000) 25-32.

[19] G. Zuo-mei Jin, W. Warren, Metall. Trans. B., 15B (1984) 3-12. 